\title{
Evaluation of the Prevalence of Hand and Wrist Complaints and ganglions in Welders
}

\section{Kaynakçılarda El ve EI Bileği Şikayetleri ve Ganglion Yaygınlığının Değerlendirilmesi}

\author{
Güray Toğral ${ }^{1}$, Cenk Şahap Altun², Nazan Küçükşahin Öztürk ${ }^{3}$, Engin Tutkun ${ }^{4}$ \\ ${ }^{1}$ Dr. Abdurrahman Yurtaslan Onkoloji Eğitim Ve Araştırma Hastanesi Ortopedi Bölümü, Ankara \\ ${ }^{2}$ Meslek Hastalıkları Hastanesi, Ortopedi Bölümü, Ankara \\ ${ }^{3}$ Meslek Hastalıkları Hastanesi, Nöroloji Bölümü, Ankara \\ ${ }^{4}$ Meslek Hastalıkları Hastanesi, Toksikoloji Bölümü,Ankara
}

Dergiye Ulaşma Tarihi: 12.04.2017 Dergiye Kabul Tarihi: 19.04.2017 Doi: 10.5505/aot.2017.85570

\section{ÖZET}

GİRIŞ ve AMAÇ: Tekrarlayıcı el postür ve hareketleri el ve el bileğinde bazı kas iskelet sistemi hastalıklarına yol açabilir. Kaynakçılar yaptıkları işin doğası nedeniyle bu hastalıklar için risk taşırlar. Kaynakçılarda Karpal Tünel Sendromu(KTS), Dupuytren Kontraktürü(DK), Tetik parmak(TP) ve DeQuervein Tendiniti(DQT) ve ganglion sıklığının araştırılması planlandı.

YÖNTEM ve GEREÇLER: Hastanemize başvuran 20 kaynakçının yaş, çalışma süresi, çalışırken dominant kullandıkları elleri kaydedildi. Kaynakçılar KTS, DK, TP, DQT semptomları ve bu semptomların şiddeti açısından sorguland. Tüm hastalar bir ortopedi uzmanı tarafından muayene edildi. Fizik muayene bulgusu olan hastalar elektromiyografi(EMG) ile nörofizyolojik olarak da değerlendirildi.

BULGULAR: Yaşları 30-54 arasında değişen, tümü erkek, 20 kaynakçı çalışmaya dahil edildi. Hastaların yaş ortalaması $45,7 \pm 6.5$, kaynakçı olarak ortalama çalışma süresi ise $24.7 \pm 8.3$ yıl idi. On altı hasta (\%80) başvuru da subjektif el ve el bileği şikâyeti belirtirken, 4(\%20) hastanın şikayeti yoktu. Ortalama şikâyet süresi 2.3 $\pm 1(1-$ 5) yıldı. 8 hasta şikayetlerinin kaynak yaparken arttığını belirtiyordu. Ortopedik muayenede aynı hastada bir ya da daha fazla bulgu olmak üzere 5 hastada tenar atrofi, 10 hastada Tinel, 5 hastada Phalen Testi pozitiflikleri saptand1. 1 hastada TP,1 hastada DK ve 2 hastada DQT ve 3 hastada ganglion kisti saptandi. EMG ile değerlendirilen 16 hastanın 3'ünde hafif, 2'inde orta, 1 hastada şiddetli tek taraflı KTS bulguları, bilateral şikâyeti olan bir hastada aktif olan elde orta diğer elde hafif KTS bulgusu saptand. TARTIŞMA ve SONUÇ: KTS kaynakçılarda önemli bir işgücü kaybı nedenidir, bu meslek grubunda hastalığın belirtileri hakkında bilinç düzeyinin arttırılması yoluyla hastalığın erken tanı ve tedavisinin sağlanması hastalığın neden olduğu işgücü kaybını azaltacaktır.

Anahtar Kelimeler: Kaynakçı, El Bileği, Şikâyet, Elektromiyografi, Ganglion

\begin{abstract}
INTRODUCTION: Repetitive hand postures and movements can lead to some musculoskeletal system diseases in the hand and wrist. Welders carry risks for these diseases because of the nature of the work they are doing. It is planned to investigate the frequency of Carpal Tunnel Syndrome (CTS), Dupuytren Contracture (DK), Trigger finger (TP), DeQuervin Tendinitis (DQT) and 3 as ganglions in the welders. METHODS: Twenty welders who applied to my hospital were recorded as age, duration of study, use of dominant in working.They were questioned for the symptoms of CTS, DK, TP, DQT and the severity of these symptoms. All patients were examined by an orthopedist. Patients with pathological physical examination findings were assessed neurophysiologically by electromyography (EMG) RESULTS: A total of 20 welders, aged 30-54, all male, were included in the study. The mean age of the patients was $45.7 \pm 6.5$ years and the average duration of the working as welder was $24.7 \pm 8.3$ years. Sixteen patients $(80 \%)$ had subjective hand and wrist complaints while $4(20 \%)$ patients had no complaints. The mean duration of complaints was $2.3 \pm 1$ (1-5) years. 8 patients stated that their complaints increased when they were welding. Orthopedic examination revealed tenor atrophy in 5 patients, tinel positivity in 10 patients, phalen test positivity
\end{abstract}


in 5 patients. Two patients were diagnosed as DQT, 1 as TP, 1as DD and 3 as Ganglions. Sixteen patients evaluated by EMG; unilateral mild CTS was detected in 3, unilateral moderate in 2, severe unilateral CTS findings in 1 patient, moderate in dominant, mild CTS in non-dominant hand of a patient who had bilateral complaints.

DISCUSSION AND CONCLUSION: CTS is a major cause of labor loss in welders, providing early diagnosis and treatment of the disease through increased awareness of the disease's symptoms in this occupational group will reduce labor force loss caused by the disease

Keywords: Welders, Wrist, Complaints, Electromyography, Ganglions

\section{GíRiş}

Karpal tünel sendromu (KTS) toplumda en sik görülen tuzak nöropatisidir. KTS'yi diğer median nöropatilerden, servikal kök ve brakiyal pleksus lezyonlarından ayırabilmek için, median sinir ve KT anatomisinin iyi bilinmesi gerekir. Hastalıkla ilişkilendirilen risk faktörlerinden birisi de kümülatif travmaya neden olabilen bir işte çalışıyor olmaktır (1). Toplumda \%1 civarında tahmin edilen KTS sıklığı tekrarlayıcı el ve el bilek hareketlerine neden olan meslek kollarında $\% 5$ 'e kadar çıkmaktadır (2).

Kaynakçılık aktif olarak elde sürekli ve uzun süreli el bilek ekstansör ve fleksör kaslarının kullanılmasını gerektiren bir işkoludur. İş sırasında elin tekrarlan ve güçlü kullanımı bileğin sürekli garip duruşu ve titreşimli hareketlere maruz kalması KTS oluşumunda risk faktörleridir (3). $\mathrm{Bu}$ çalışmada Ankara Meslek Hastalıkları Hastanesine rutin meslek sağlık kontrolü için başvuran kaynakçılarda el ve el bilek şikayetleri ile KTS, De Quervein tenosinoviti (DQT), tetik parmak (TP), Dupuytren kontraktürü (DK) ve ganglion siklığının değerlendirilmesi planland. Ganglion kisti eklem kapsülünden herniasyon gösteren içi eklem sıvis1 dolu bir kisttir (3). Gangilion el ve el bileği çevresinde bulunan en yaygın tümördür. Gangilion iyi huylu bir tümöral oluşum olup genellikle el bileğinde soliter lezyon olarak saptanır. Ganglionlar her yaşta görülebilmekle birlikte en sik 2-4 dekatta ortaya çıkar. En sık yerleşim yeri el bileği dorsalidir. Günlük hayatta elini sık kullanan meslek guruplarında daha sik rastlanmaktadır. El bileği ağrı şikâyeti ile başvuran hastalarda özellikle dikkatli muayene şarttır. Bu çalışma yapılacak daha büyük bir çalışma için ön çalışma olarak planlandı.

\section{YÖNTEM}

Ankara Meslek Hastalıkları hastanesine başvuran 20 kaynakçı çalışmaya dahil edildi. Hastaların yaş, cinsiyet, meslekte çalışma süreleri kaydedildi. Hastalar, eşlik eden romatizmal hastalık, diyabet ve tiroid hastalıkları açısından sorgulandı. Tüm hastalara, aktif el(yazı yazarken kullanılan el), el ve bilek şikayetleri, varsa şikayetlerinin niteliği(ağr1-uyuşukluk-güçsüzlük-

beceriksizlik), şikayetlerinin olma zamanını(gece-gündüz), şikayetlerinin süresi, kaynak yaparken şikayetlerinin artıp artmadığını sorgulayan bir anket uygulandı. Tüm hastalar ayn1 ortopedist tarafindan KTS (Tenar atrofi, Tinel testi ve Phalen testi ile), TP, DK ve DQT (Finkelstein Testi ile) açısından muayene edildi. Pozitif muayene bulgusu ve/veya şikâyeti olan tüm hastalar elektromiyografi (EMG) ile nörofizyolojik olarak değerlendirildi.

\section{BULGULAR}

Yaşları 30-54 arasında değisşen, tümü erkek, 20 kaynakçı çalışmaya dahil edildi. Hastaların yaş

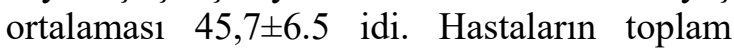
çalışma süreleri Tablo 1'de özetlendi. Kaynakçı olarak ortalama çalışma süresi $24.7 \pm$ 8.3 y1ld1. Özgeçmişinde eklem romatizması olan $2(\% 10)$, diabet olan 3 (\%15), tiroid olan 3 kişi (\%15) vardı. 18(\%90) kişi dominant el olarak sağ elini tanımladı. 
Tablo 1: Kaynakçıların çalışma sürelerinin dağılımı

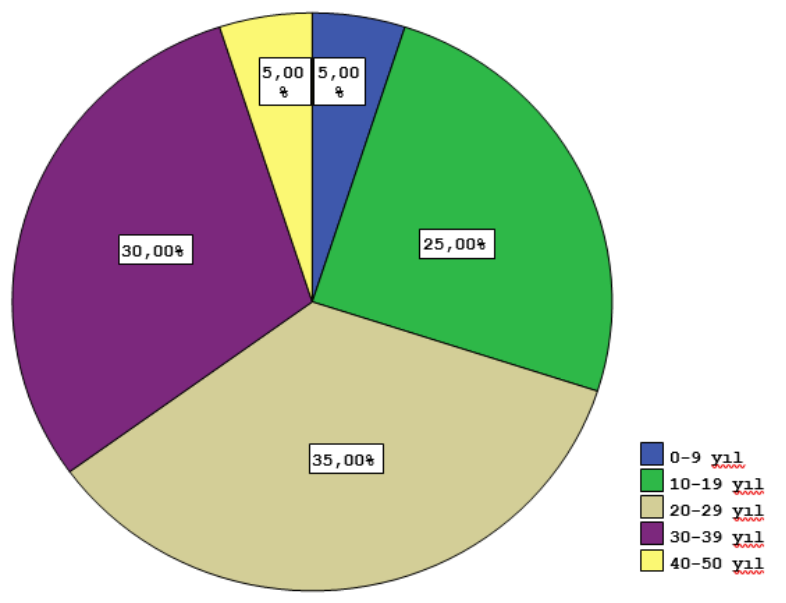

Onaltı hasta (\%80) subjektif el ve el bileği şikâyeti belirtirken, 4(\%20) hastanın şikayeti yoktu. Şikâyeti olan 16 hastanın 7'si sadece sağ, 3'ü sadece sol 6'sı her iki elinde de şikâyet olduğunu belirtiyordu. Ortalama şikâyet süresi $2.3 \pm 1(1-5) \quad$ y1ldı. Şikayetlerin niteliği değerlendirildiğinde; ağrı, uyuşma, güçsüzlük, beceriksizliğin başlıca yakınmalar olduğu görüldü. Tablo 2'de hastaların şikayetlerinin dağılımı özetlendi. Şikâyeti artış zamanı 10 hastada gece, 6 hastada gündüzdü. 8 hasta şikayetlerinin kaynak yaparken arttığını belirtiyordu.

Tablo2: Kaynakçıların el ve bilek bölgesi şikayetlerinin dağılımı

\begin{tabular}{|l|l|l|l|}
\hline & Var (n) & Yok(n) & Toplam(n) \\
\hline Ağr1 & 10 & 10 & 20 \\
\hline Uyuşma & 8 & 12 & 20 \\
\hline Güçsüzlük & 6 & 14 & 20 \\
\hline Beceriksizlik & 2 & 18 & 20 \\
\hline
\end{tabular}

Yapılan ortopedik muayenelerinde şikâyeti olmayan 4 hasta ile şikâyeti olan 6 hasta normal olarak değerlendirildi. Ortopedik muayenede ayn 1 hastada bir ya da daha fazla bulgu olmak üzere 5 hastada tenar atrofi, 10 hastada Tinel, 5 hastada Phalen Testi pozitiflikleri saptandi. 1 hastada tetik parmak,1 hastada DK, 2 hastada DQT ve 3 hastada ganglion saptand. Hepsi dominant olarak kullandıkları sağ elde idi. Hastaların Ortopedik muayene bulguları Tablo 3'te özetlendi. 
Tablo3: Hastaların ortopedik muayene bulgularının dağılımı

\begin{tabular}{|l|l|l|}
\hline & Var / Pozitif (n ) & Yok/Negatif (n ) \\
\hline Tenar atrofi & 5 & 15 \\
\hline Tinel testi & 10 & 10 \\
\hline Phalen testi & 5 & 15 \\
\hline Tetik parmak & 1 & 19 \\
\hline DeQuervein Tendiniti & 1 & 19 \\
\hline Duputren Kontraktürü & 2 & 18 \\
\hline
\end{tabular}

EMG ile değerlendirilen 16 hastanın 9'unda normal olarak değerlendirildi. EMG bulgusu olan 7 hastanın değerlendirildiğinde 3 hastada hafif, 2'sinde orta, 1 hastada şiddetli tek taraflı KTS bulguları, bilateral şikâyeti olan bir hastada aktif olan elde orta diğer elde hafif
KTS bulgusu saptandi. Sol el bileğinde orta derecede KTS saptanan bir hasta 3 yıl önce sağ el bileğinden KTS nedeniyle opere olmuştu. Karpal tünel sendromu düşündüren muayene bulgusu mevcudiyeti ile EMG sonuçlarının karşılaştırılması Tablo 4'de özetlendi.

Tablo 4: Karpal tünel sendromu düşündüren muayene bulgusu mevcudiyeti ile EMG sonuçlarının karşılaştırılması *Elektromyelografi **Karpal Tünel Sendromu

\begin{tabular}{|l|l|l|}
\hline \multirow{2}{*}{} & \multicolumn{2}{|l|}{ Karpal tünel sendromu düşündüren } \\
muayene bulgusu
\end{tabular}

\section{TARTIŞMA}

KTS meslek ile ilişkili de olabilen yaygın bir sağlik problemidir (5-11). Titreşim içeren, el bileğini zorlayan hareketlerin sik yapılmasını; el ve el bileğinin uzun süre sabit pozisyonda tutulmasinı gerektiren mesleklerde çalışan bireylerde KTS sıklığı artmaktadır (12). Kaynakçıllk da bu tanımlamaya uyan bir meslek grubudur. Nitekim bu çalışmada hastaneye özellikle el-bilek şikâyeti nedeniyle başvurmamış olan 20 hastanın 16'sında subjektif şikayetlerin olması, 10'unda KTS düşündüren muayene bulguları saptanması, 7 hastanın EMG incelemesinde farklı ağırlıkta KTS saptanması bu görüşü desteklemektedir.

El bileği zorlandığında ganglion kistinin içeriğindeki sıvı artar kist büyür, istirahat ile sıv1 azalır kist küçülür. Ganglion kistinin Adress for correspondence: Onkoloji Hastanesi Ortopedi Ve Travmatoloji Kliniği Kat 206580 Ankara - Türkiye e-mail: dr guray@hotmail.com

Available at www.actaoncologicaturcica.com

Copyright $\odot$ Ankara Onkoloji Hastanesi neden oluştuğu bugün halen tam olarak bilinmemektedir. Oluş mekanizması hakkında farklı teoriler mevcuttur. İlk teori ganglionun el bileği eklem kapsülünden (eklemdeki sinovyal dokudan herniye) herniye bir kist olduğu şeklindedir. Fakat kist içinde sinovyal doku olmaması bu teoriyi zayıflatmıştır $(13,14,15)$. İkinci teori 'kapsüler yırtık' teorisidir. Buna göre eklem kapsülünde oluşan hasar sonras1 periartiküler alana eklem sivis1 kaçağı olmaktadır. 1989 da Watson ve ark. ganglionun periskafoid ligaman zedelenmesine bağlı gelişen sekonder bir olgu olduğunu öne sürmüştürler (16). El bileği ganglionları daha sıklıkla genç hastalarda gözlenirken, eldeki ganglionlar ileri yaş hastalarda daha s1k saptanır (17). Lezyon genellikle asemptomatiktir ve tedavi kozmetik nedenlerle yap1lır, bununla birlikte ganglion kistinin el bileğinde diğer kitle oluşturan sebeblerden 
ayırımının yapılması önemlidir (Dev hücreli tendon tümörü, lipom, tenosinovit v.b.). Kistlerin oluşum mekanizması halen tam olarak açıklığa kavuşturulamamıştır. Ancak çalışmamızda 20 hastanın 3'ünde ve tümünde dominant elde saptanması, dikkat çekicidir. Bu hasta grubunda yapılacak ileri çalışmalar ganglion kisti oluşumundaki patogenezi açıklamada faydalı olabilir.

Hasta sayısının azlığı, çalışanların günlük çalışma saatlerinin ve çalışma yoğunluklarının

\section{REFERANSLAR}

1. Kouyoumdjian JA, de Araújo RG. Carpal tunnel syndrome and manual milking: nerve conduction studies in 43 cases. Arq Neuropsiquiatr 2006; 64:747-9

2. Roquelaure $\mathrm{Y}, \mathrm{Ha} \mathrm{C}$, Nicolas G, et al. Attributable risk of carpal tunnel syndrome according to industry and occupation in ageneral population. Arthritis Rheum 2008; 59:1341-8)

3. Clay NR, Clement DA. The treatment of dorsal wrist ganglia by radical excision. J Hand Surg Br. 1988; 13:187-91.

4. Ulusal Araştırma Konseyi. Kas-iskelet bozuklukları ve İşyeri: Bel ve kas-iskelet hastalıkları Ekstremite Üst. Washington DC: National Academy Press, 2001. Ulusal Bilimler Akademisi.

5. Yagev Y, Gringolds M, Karakis I, Carel RS. Carpal tunnel syndrome: under-recognition of occupational risk factors by clinicians. Ind Health 2007; 45:8202.

6. Maghsoudipour M, Moghimi S, Dehghaan F, RahimpanahA. Association of occupational and non-occupational riskfactors with the prevalence of work related carpal tunnel syndrome. J Occup Rehabil 2008; 18:152-6

7. Aroori S, Spence RA. Carpal tunnel syndrome. Ulster Med J 2008; 77:6-17.

8. Lewis C, Mauffrey C, Newman S, Lambert A, Hull P. Current concepts in carpal tunnel syndrome: a review of the literature. Eur J Orthop Surg Traumatol 2010; 20:445-52. belirtilmemiş olması, çalışmanın prospektif olmaması çalışmadaki kısıtlılıklardır. Kaynak işçiliği el ve el bileği kas-iskelet sistemi hastalıkları gelişmesinde risk faktörüdür, bu işçilerin erken tanı ve tedavi için düzenli sorgulanması ve muayenesi iş verimliliği ve işçi sağlığı için önemlidir. Bu konuda ileri çalışmalara ihtiyaç vardır.

\section{Conflict of interest: None}

9. Hagberg M, Morgenstern H, Kelsh M. Impact of occupations and job tasks on the prevalence of carpal tunnel syndrome. Scand J Work Environ Health 1992; 18:337-45.

10. Bağatur EA, Dervişoğlu S, Albayrak M, Doğan A, Mumcuoğlu İE, Zorer G. İdiyopatik karpal tünel sendromlu hastalarda transvers karpal ligaman ve fleksörtenosinovyum örneklerinde histopatolojik çalışma. Eklem Hastalik Cerrahisi 2006; 17:72-8

11. Çiftdemir M, Çopuroğlu C, Özcan M, Çavdar L. Carpal tunnel syndrome in manual tea harvesters. Eklem Hastalik Cerrahisi. 2013; 24:12-7.

12. Spahn G, Wollny J, Hartmann B, Schiele R, Hofmann GO. Metaanalysis for the evaluation of risk factors for carpal tunnel syndrome (CTS) Part II. Occupational risk factors.Z Orthop Unfall. 2012; 150:516-24.

13. Dias JJ, Dhukaram V, Kumar P. The natural history of untreated dorsal wrist ganglia and patient reported outcome 6 years after intervention. J Hand Surg Eur Vol. 2007; 32:502-8.

14. Minotti P, Taras JS. Ganglion cysts of the wrist. J Hand Surg Am. 2002; 2:102-7.

15. Gude W, Morelli V. Ganglion cysts of the wrist: Pathophysiology, clinical picture, and management. Curr Rev Musculoskelet Med. 2008; 1:205-11.

16. Watson HK, Rogers WD, Ashmead D 4th. Reevaluation of the cause of the wrist ganglion. J Hand Surg Am. 1989;14:812-17.

17. Sebastian Kuliński, Olga Gutkowska, Sylwia Mizia, Jerzy Gosk. Ganglions of the hand and wrist: Retrospective statistical analysis of 520 cases. Adv Clin Exp Med. 2017;26(1):95-100. 